13.4

\title{
Полоса синхронизации магнетрона
}

\author{
( Ю.Д. Черноусов ${ }^{1,2}$, И.В. Шеболаев ${ }^{1,2}$, И.М. Икрянов ${ }^{1}$, В.А. Болотов ${ }^{2}$, Ю.Ю. Танашев $^{2}$, Л.Э. Медведев ${ }^{3}$, \\ Р.В. Воскобойников ${ }^{3}$ \\ ${ }^{1}$ Институт химической кинетики и горения им. В.В. Воеводского СО РАН, Новосибирск, Россия \\ ${ }^{2}$ Институт катализа им. Г.К. Борескова СО РАН, Новосибирск, Россия \\ ${ }^{3}$ Институт ядерной физики им. Г.И. Будкера СО РАН, Новосибирск, Россия \\ E-mail: chern@catalysis.ru
}

Поступило в Редакцию 26 сентября 2019г.

В окончательной редакции 26 сентября 2019 г.

Принято к публикации 4 октября 2019г.

Измерена полоса синхронизации магнетрона внешним сверхвысокочастотным (СВЧ) сигналом. Для измерений использован СВЧ-генератор на базе магнетрона бытовой печи с широким диапазоном изменения импульсной и средней СВЧ-мощности. Показано, что для синхронизации в заданной полосе требуется на порядок меньшая СВЧ-мощность, чем следует из публикаций последнего времени. Приведен метод измерения параметров резонатора при большом коэффициенте связи с линией.

Ключевые слова: магнетрон, синхронизация, добротность, коэффициент связи.

DOI: 10.21883/PJTF.2020.01.48862.18051

Магнетроны - сверхвысокочастотные (СВЧ) автогенераторы - отличаются высокой надежностью, простотой управления, относительной дешевизной [1]. При импульсном питании с их помощью возможно формирование как коротких СВЧ-импульсов (в микросекундном диапазоне длительности), так и относительно длинных (в миллисекундном диапазоне). При работе в режиме синхронизации внешним СВЧ-сигналом магнетроны характеризуются высокой стабильностью частоты. В последнее время интерес к магнетронам значительно возрос, интенсивно изучается вопрос использования этих СВЧ-приборов для целей ускорительной и СВЧ-техники [1-4], а также нестандартных приложений, например микроволновой химии [5].

Полоса синхронизации (ПС) - диапазон частот, в пределах которого частота колебаний автогенераторамагнетрона равна частоте внешнего СВЧ-сигнала, определяется мощностью синхронизирующего генератора. Существенно, чтобы в процессе работы собственная частота магнетрона, зависящая от многих параметров (анодного напряжения, анодного тока, температуры анодного блока резонаторов), не выходила за границы ПС. По этой причине величина ПС при заданной мощности синхронизирующего сигнала является важным параметром для приложений, определяет минимальную величину мощности синхронизирующего генератора.

Соотношение для ПС приведено в работах $[2,4,6]$, где оно получено из дифференциальных уравнений Адлера для фазы синхронизируемого автогенератора [6]. В других публикациях также приводится выражение для ПС, где оно получено из соотношения для величины полосы затягивания частоты магнетрона внешней отражающей нагрузкой $[7,8]$. Из формул, приведенных в указанных публикациях, следуют различающиеся в 4 раза значения для величины ПС при заданной мощности генератора. Соответственно при заданной ПС в 16 раз отличается необходимая мощность синхронизирующего СВЧ-генератора. Разница существенна, и для использования в приложениях необходимо экспериментальное уточнение зависимости ПС от мощности синхросигнала. В настоящей работе проведены такие измерения, и в качестве базового проверяемого соотношения взято выражение для ПС $\Delta F$, приведенное в работе Райнера [8]:

$$
\Delta F=\frac{2 f_{0}}{Q_{e x t}} \sqrt{\frac{P}{P_{0}}} .
$$

Здесь $f_{0}, Q_{\text {ext }}, P_{0}-$ соответственно рабочая частота, внешняя добротность и выходная мощность магнетрона, $P$ - мощность генератора синхросигнала.

Одной из трудностей при проверке соотношения (1) является измерение внешней добротности резонансной системы магнетрона. Связь резонатора-магнетрона с линией значительно больше критической, поскольку разработчики стремились к возможно более высокому КПД прибора [1]. При большой пересвязи форма зависимости модуля коэффициента отражения от частоты слабо выражена, что практически исключает измерение добротности по отраженному сигналу. Измерение добротности по проходной схеме также исключено, поскольку магнетрон имеет только один выход. В настоящей работе измерение параметров магнетрона проведено комбинированным методом: применены измерительная линия (ИЛ) и анализатор цепей. Магнетрон устанавливался на волновод [5], волновод подсоединялся к волноводной ИЛ, в ИЛ от анализатора цепей вводился СВЧ-сигнал, и в полосе частот с помощью того же анализатора цепей измерялся СВЧ-сигнал с передвижного зонда ИЛ. Использовались свойства стоячей волны в линии перед резонатором-магнетроном, формируемой при его возбуждении СВЧ-сигналом. 

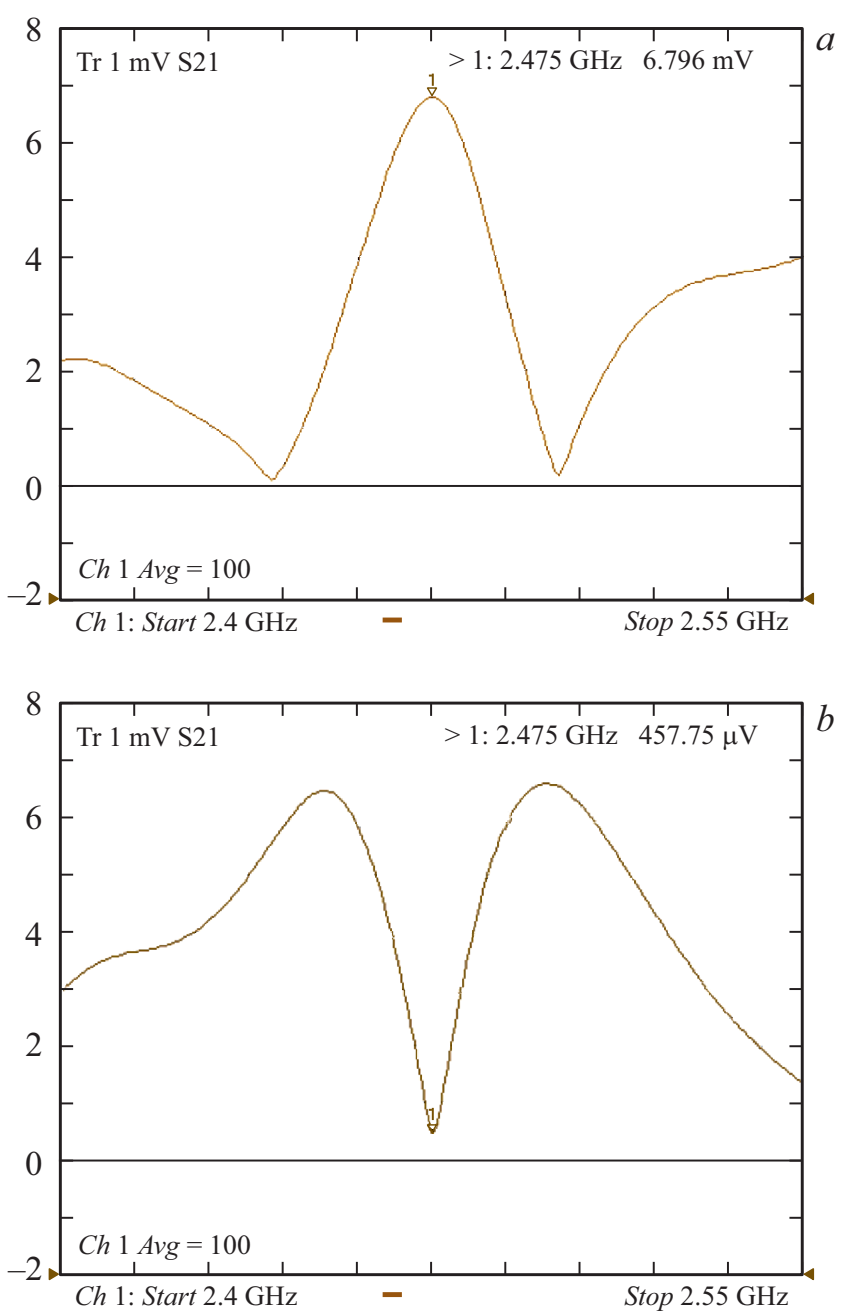

Рис. 1. Зависимость амплитуды СВЧ-сигнала от частоты с зонда ИЛ, расположенного в минимуме $(a)$ и в максимуме $(b)$ стоячей волны при отстройке. Для измерений использовались измерительная линия P1-7 и анализатор цепей Agilent N5230A.

Исходя из соотношения для зависимости коэффициента отражения резонатора от частоты [9] можно показать, что, если зонд находится в минимуме стоячей волны при отстройке, зависимость амплитуды измеряемого с зонда сигнала от частоты $f$ и коэффициента связи $\beta$ имеет вид

$$
\Upsilon_{\min }(f, \beta) \approx K\left(\frac{2 \beta}{1+\beta}\right) \frac{1}{\sqrt{1+4 Q_{L}^{2}\left(\delta f / f_{0}\right)^{2}}} .
$$

Здесь $K-$ нормирующий коэффициент, $Q_{L}-$ нагруженная добротность, $f_{0}-$ резонансная частота резонатора (колебательной системы магнетрона), $\delta f / f_{0}-$ относительная расстройка, $\delta f=f-f_{0}$. Вид кривой (2) аналогичен виду амплитудно-частотной характеристики резонатора, измеряемой по проходной схеме. Измеряя разность частот $\Delta f$ на высоте $1 / \sqrt{2}$ от максимального значения, можно определить полосу пропускания и соответственно нагруженную добротность резонатора $Q_{L}=f_{0} / \Delta f$. Отметим, что полосовая характеристика СВЧ-тракта зонда ИЛ имеет резонансный характер.
Кроме того, положение минимума стоячей волны в ИЛ зависит от частоты. Эти обстоятельства приводят к искажению формы и симметрии регистрируемой кривой, уменьшению $\Delta f$ и завышению величины добротности измеряемого резонатора. Поправочный коэффициент следует определять, измеряя по описанной процедуре добротность макетного резонатора с известной добротностью, близкой к добротности магнетрона.

В максимуме стоячей волны при отстройке зависимость амплитуды измеряемого с зонда сигнала от частоты и коэффициента связи имеет вид

$$
\Upsilon_{\max }(f, \beta) \approx K\left|-2+\frac{2 \beta}{1+\beta} \frac{1}{\Omega_{L}}\right| .
$$

Здесь $\Omega_{L}=1+2 j Q_{L} \delta f / f_{0}[9]$. Для измерения коэффициента связи $\beta$ следует измерить величину сигнала с зонда в минимуме и максимуме стоячей волны при отстройке на резонансной частоте. На резонансной частоте $\Upsilon_{\min }\left(f_{0}, \beta\right) / \Upsilon_{\max }\left(f_{0}, \beta\right)=\beta$.

Для исследованного магнетрона 2М246 экспериментальные кривые с зонда ИЛ, расположенного соответственно в минимуме и максимуме стоячей волны при отстройке, приведены на рис. $1, a$ и $b$. По значениям на резонансе была получена величина $\beta \approx 15$. С учетом поправки на характеристики зонда ИЛ, определенной с помощью макетного резонатора, по кривой на рис. $1, a$ найдено $Q_{L} \approx Q_{\text {ext }} \approx 100$.

Соотношение (1) проверялось на стенде, схема которого приведена на рис. 2. Для измерений использован СВЧ-генератор на базе коммерческого магнетрона 2M246 бытовой печи с широким диапазоном изменения импульсной и средней СВЧ-мощности. Магнетрон своим выводом установлен на волновод [5], и сформированный магнетронный блок 1 (рис. 2) подсоединен к волноводному трехпортовому циркулятору 2 . К циркулятору 2 также подсоединены поглощающая согласованная нагрузка 3 и коаксиальный трехпортовый циркулятор 4. К портам циркулятора 4 подсоединены высокостабильный СВЧ-генератор 5 и согласованная нагрузка 6.

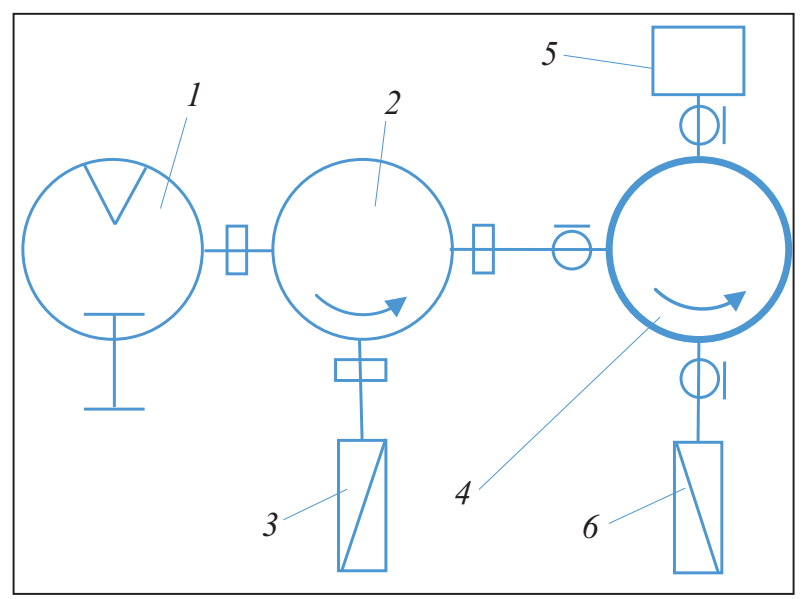

Рис. 2. СВЧ-схема измерения полосы синхронизации. Пояснения в тексте. 


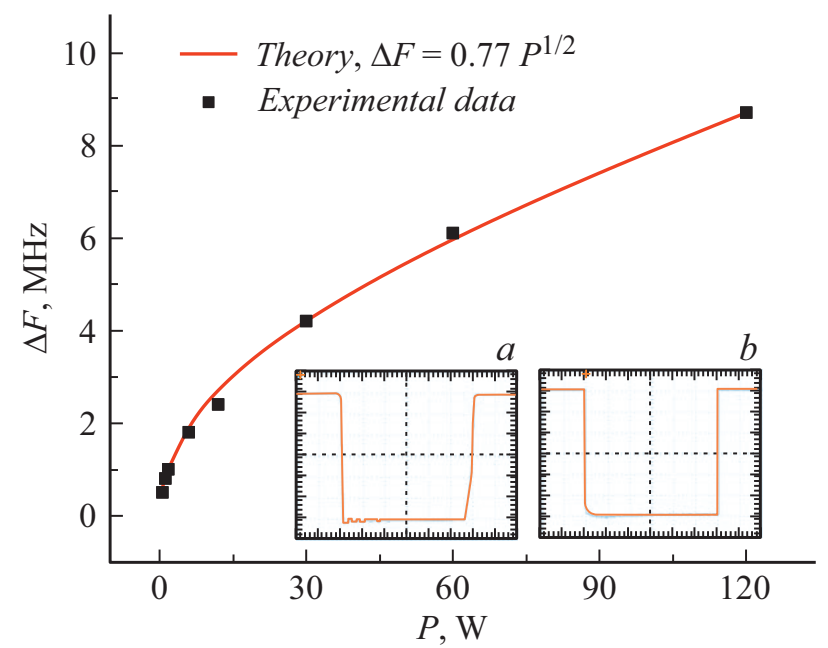

Рис. 3. Зависимость полосы синхронизации $\Delta F$ от мощности синхронизирующего генератора $P$. Импульсная мощность магнетрона $P_{0}=5 \mathrm{~kW}$, частота $f_{0}=2472 \mathrm{MHz}, Q_{\text {ext }} \approx 90$. На вставке $a-$ огибающая СВЧ-импульса магнетрона, длительность $6 \mu \mathrm{s}, P_{0}=4 \mathrm{~kW}$; на вставке $b-$ огибающая СВЧ-импульса магнетрона, длительность $60 \mathrm{~ms}, P_{0}=2 \mathrm{~kW}$.

СВЧ-мощность магнетрона 1 через циркулятор 2 поступает в нагрузку 3. СВЧ-мощность генератора 5 через циркуляторы 4, 2 поступает в колебательную систему магнетрона 1 для его синхронизации. Измерялась зависимость полосы синхронизации магнетрона 1 от мощности СВЧ-генератора 5. Магнетрон 1 работал в импульсном режиме, СВЧ-генератор 5 - в непрерывном. Наличие синхронизации определялось с помощью высокодобротного резонатора, включенного по проходной схеме [7]. СВЧ-сигнал в резонатор подавался с зонда, установленного на нагрузке 3. Прошедший резонатор СВЧ-сигнал детектировался и подавался на осциллограф. В режиме синхронизации - при совпадении частот колебаний магнетрона и синхросигнала - форма огибающей имеет стандартный вид [7], огибающая стабильна, без модуляции и искажений. При выходе из режима синхронизации на огибающей наблюдались не повторяющиеся от импульса к импульсу выбросы, форма искажалась.

Расчетная и экспериментальная зависимости полосы синхронизации магнетрона от мощности синхросигнала приведены на рис. 3. Экспериментальные данные хорошо описываются зависимостью (1) при $Q_{e x t} \approx 90$. Это значение близко к приведенному выше измеренному значению добротности резонансной системы магнетрона. Работу магнетрона в импульсном режиме характеризуют осциллограммы на вставках к рис. 3.

В заключение отметим, что в работе экспериментально исследована зависимость полосы синхронизации магнетрона от мощности внешнего СВЧ-сигнала. Расчетная формула (1), приведенная в работе Райнера [8], подтверждена экспериментом и может быть использована для технических расчетов. Соотношение Адлера $[2,4,6]$ завышает величину СВЧ-мощности для синхронизации магнетрона в заданной полосе частот более чем на порядок. Также показано, что комбинированный метод измерения параметров за счет использования измерительной линии и анализатора цепей позволяет при наличии только одного входа измерять добротность и коэффициент связи пересвязанных резонаторов.

\section{Финансирование работы}

Работа выполнена за счет гранта Российского научного фонда (проект № 17-7330032).

\section{Конфликт интересов}

Авторы заявляют, что у них нет конфликта интересов.

\section{Список литературы}

[1] Vyas S.K., Verma R.K., Maurya S., Singh V.V.P. // Frequenz. 2016. V. 70. N 9. P. 455-462.

[2] Dexter A.C. // Proc. of LINAC 2014. Geneva, Switzerland, 2014. P. 751-755.

[3] Kazakevich G., Johnson R., Neubauer M., Lebedev V., Schappert W., Yakovlev V. // Proc. of IPAC 2017. Copenhagen, Denmark, 2017. P. 4386-4388.

[4] Wang H., Rimmer R.A., Nelson R., Neubauer M., Dudas A., Coriton B.R., Moeller C.P. // Proc. of IPAC 2019. Melbourne, Australia, 2019. P. 2233-2236.

[5] Черноусов Ю.Д., Иванников В.И., Шеболаев И.В., Болотов В.А., Танашев Ю.Ю. // ПТЭ. 2019. № 2. С. 136-141.

[6] Adler R. // Proc IRE. 1946. V. 34. P. 351-357.

[7] Лебедев И.В. Техника и приборы СВЧ. М.: Высш. шк., 1970. 1972. T. 1. 439 c. T. 2.375 c.

[8] Райнер М.M. // Вопр. радиоэлектроники. Сер. 1. Электроника. 1961. № 8. С. 12-26.

[9] Черноусов Ю.Д., Иванников В.И., Шеболаев И.В., Левичев А.Е., Павлов В.М. // Радиотехника и электроника. 2010. T. 55. № 8. C. 923-929. 